\title{
DESENVOLVIMENTO DE UM SISTEMA AUTOMATIZADO PARA A FABRICAÇÃO DE FILMES AUTOMONTADOS
}

Francisco Trivinho-Strixino e Ernesto C. Pereira*

Departamento de Química, Universidade Federal de São Carlos, CP 676, 13560-970 São Carlos - SP

Luis Roberto C. Lopes

Departamento de Física, Universidade Federal de São Carlos, CP 676, 13560-970 São Carlos - SP

Recebido em 8/7/03; aceito em 29/10/03; publicado na web em 27/05/04

DEVELOPMENT OF AN AUTOMATED DEVICE FOR FABRICATION OF SELF-ASSEMBLED FILMS. In this technical note, we describe the construction of a low-cost computer controlled device for layer-by-layer film fabrication. The software allows to control multiple material deposition, washing and drying steps and the time for each operation. To test the device, we produced and characterized self-assembled films of conductive polymers by alternating poly(o-methoxyaniline) (POMA) and poly(3thiophene acetic acid) (PTAA) via the layer-by-layer technique.

Keywords: layer-by-layer technique; Langmuir-Blodgett technique; automated device.

\section{INTRODUÇÃO}

A procura por novos materiais que possam ser modificados em nível molecular tem sido objetivo de numerosas pesquisas no mundo inteiro. Estas pesquisas envolvem o uso de materiais orgânicos cujas propriedades (elétricas, ópticas e magnéticas) os tornam potencialmente úteis na fabricação de dispositivos inovadores ${ }^{1,2}$. A técnica de Langmuir-Blodgett (LB) tem sido a mais utilizada para tais propósitos, uma vez que permite a construção de sistemas de multicamadas com um controle de espessura na ordem de nanômetros, além de possibilitar o processamento de filmes com orientação e estruturas moleculares bem definidas. Outra técnica, denominada "layer-by-layer" (LBL) 1,2, vem sendo utilizada para o processamento de filmes finos através da automontagem de multicamadas poliméricas diferenciadas. $\mathrm{O}$ aparato experimental exigido é mais simples que para a técnica LB, o que aumenta o interesse comercial.

Experimentalmente, o método de automontagem consiste em submergir o substrato num béquer contendo a solução do policátion ou do poliânion por um determinado período de tempo (geralmente alguns min) ${ }^{3-5}$. Uma vez em contato com a solução de depósito, as moléculas carregadas dos poliíons adsorvem-se na superfície do subtrato por interação eletrostática. O substrato é, então, lavado em uma solução com $\mathrm{pH}$ próximo ao da solução polimérica para remover as moléculas que não foram satisfatoriamente adsorvidas, sendo em seguida seco ao ar ou jato de $\mathrm{N}_{2}$. O sistema substrato + filme está agora carregado eletrostaticamente, o que permite a adsorção de uma nova camada carregada com carga oposta através da imersão em outra solução polimérica. Após a adsorção desta segunda camada, o substrato é novamente lavado e seco (Figura 1). Estruturas de multicamadas podem ser construídas repetindo-se as etapas acima, de modo a se obter o número desejado de bicamadas, uma vez que, aparentemente, não há limitações na quantidade de camadas que podem ser depositadas ${ }^{1,3}$.

São características desta técnica através do procedimento manual, o longo período de preparo dispensado e a necessidade do intermédio de um operador, o que dá à técnica aspectos artesanais de baixa eficiência, diminuindo a reprodutibilidade dos filmes. A fabri-

*e-mail: decp@power.ufscar.br

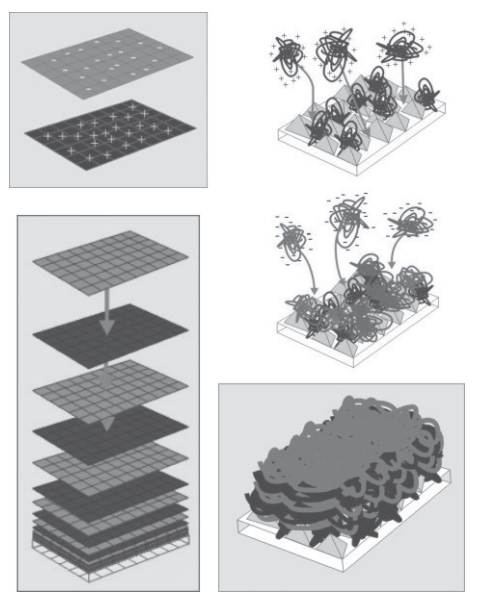

Figura 1. Ilustração esquemática da obtenção de filmes de multicamadas, através da interação eletrostática entre camadas com elevado controle molecular

cação de filmes por esse método exige um procedimento repetitivo e que pode durar muitas horas, dependendo do número de bicamadas a serem depositadas. Diversos fatores tornam esta tarefa morosa e desgastante, como, por exemplo, o fato de cada camada demorar, em alguns casos, de 5 a 10 min para se formar. Desta forma, preparar um filme automontado de 40 bicamadas pode levar várias horas. Considerando que se trata de uma tarefa puramente mecânica, a construção de um sistema automatizado para a preparação de filmes automontados possibilita a otimização no processo de obtenção destes filmes, eliminando suas características artesanais e viabilizando sua implementação comercial. Com este objetivo, foi desenvolvido um dispositivo para a preparação de filmes automontados totalmente automatizado e controlado por computador. Existem no mercado sistemas automatizados para a fabricação de filmes automontados comerciais, porém seu custo ainda é muito elevado. A diminuição de custos em dispositivos para laboratório já foi proposta por Nabok et $a l .{ }^{6}$. Em tal proposta, o sistema desenvolvido foi baseado na construção de todo um componente mecânico para o deslocamento do 
porta-amostra. No nosso caso, por outro lado, preferimos utilizar um registrador $\mathrm{X}-\mathrm{Y}$, equipamento comum nos laboratórios e que, atualmente, está obsoleto e em desuso. Alguns dos componentes do nosso dispositivo, como uma válvula solenóide e um microcomputador PC Pentium ${ }^{\circledR} 200 \mathrm{MHz}$ (plataforma Windows 98), estavam disponíveis e desativados no laboratório por serem obsoletos para suas funções normais. Além destes equipamentos, utilizamos uma placa conversora DA de baixo custo, construída no laboratório. O reaproveitamento destes componentes possibilitou a construção de um dispositivo de baixo custo, permitindo a implementação da técnica de automontagem para uso científico ou comercial.

\section{COMPONENTES DO DISPOSITIVO}

\section{Registrador X-Y}

O registrador utilizado possui a vantagem de poder ser colocado na posição vertical, através de uma base de sustentação. Além disso, seu servo mecanismo apresentava ótima sensibilidade e um torque suficiente para carregar o substrato com uma velocidade lenta e controlada.

Todo o conjunto foi mantido no interior de um gabinete de acrílico (Figura 2a). Este reservatório tem como função proteger o sistema de um eventual acidente externo, além de minimizar a quantidade de particulados no interior da câmara, permitindo a construção de filmes LBL em escala analítica.
A

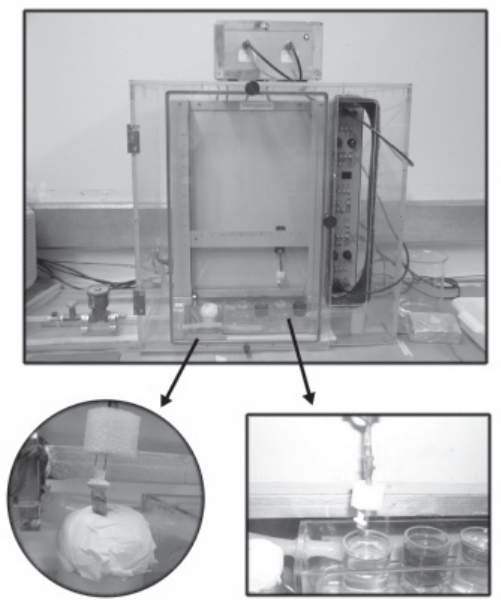

B

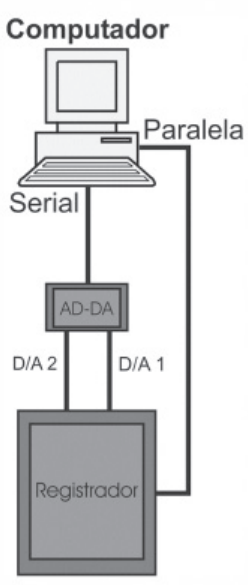

Figura 2. a) Foto do registrador utilizado como servo mecânico para o desenvolvimento do dispositivo automatizado. b) Esquema da conexão do computador, da placa controladora DA e do registrador

\section{Controladora DA}

A placa controladora DA é um conversor de sinal digital/ analógico, que tem por função manter uma comunicação entre o computador e o registrador. Este dispositivo foi conectado externamente ao computador por meio das saídas: serial (COM2) e paralela (LPT1) (Figura 2b). O sinal de 16 bits proveniente do computador atravessa o conversor DA, e este conecta-se ao registrador X-Y pelas entradas $\mathrm{X}$ e Y. A resolução de saída obtida é de $91 \mu \mathrm{V}$ (considerando uma diferença de potencial de $\pm 3 \mathrm{~V}$ ), o que é mais que suficiente para permitir um deslocamento suave dos braços do registrador. Uma outra saída digital adicional, instalada no interior do compartimento que abriga a placa conversora DA, permitiu o acionamento e controle de uma válvula solenóide através da porta paralela do computador. As especificações da válvula solenóide utilizada na montagem são: Marca Asco $^{\circledR}$, Voltagem: 220 240V, Freq.: 50 60 Hz, Potência: 6 Watts, Conexão 0,250 pol, Orifício 0,125 pol, Pressão: $9 \mathrm{~kg} / \mathrm{cm}^{2}$, Fluidos: ar, gás, água e óleo.

Com essa configuração, foi possível reproduzir um movimento uniforme e com velocidade constante do "porta-amostra" através de um eixo de coordenadas cartesianas X-Y.

\section{Software}

Juntamente com o circuito eletrônico, foi desenvolvido um “driver" compatível com o software HP-VEE ${ }^{\circledR}$ (versão Windows $98^{\circledR}$ ), que permitisse o funcionamento e o controle da placa DA através do computador. Este "driver" tem por função converter números inteiros em sinais elétricos na faixa de $\pm 3 \mathrm{~V}$ que são, em seguida, enviados para a conversora DA. Esta faixa de potencial permite a movimentação do servo mecânico em todas as direções dos eixos cartesianos. Para evitar que o movimento do braço mecânico fosse brusco, a registradora $\mathrm{X}-\mathrm{Y}$ foi regulada para um fundo de escala compatível e que suavizasse o movimento.

Tendo este "driver" como ponto de partida, foi desenvolvido um programa de rotinas que controlasse estes números inteiros. Através do programa de interfaciamento desenvolvido no ambiente $\mathrm{HPVEE}^{\circledR}$ foi possível construir um programa que permitisse total controle sobre o dispositivo: tempo de deposição, lavagem, secagem e do número de bicamadas. Com a utilização deste software pode-se monitorar concomitantemente o estágio de preparo e o tempo programado em cada etapa. Além disso, o dispositivo possibilita um movimento mecânico de até oito estágios horizontais, como, por exemplo, um sistema com 7 soluções precursoras e uma solução de lavagem, aumentando ainda mais a versatilidade do aparelho. O fluxograma do programa está ilustrado na Figura 3.

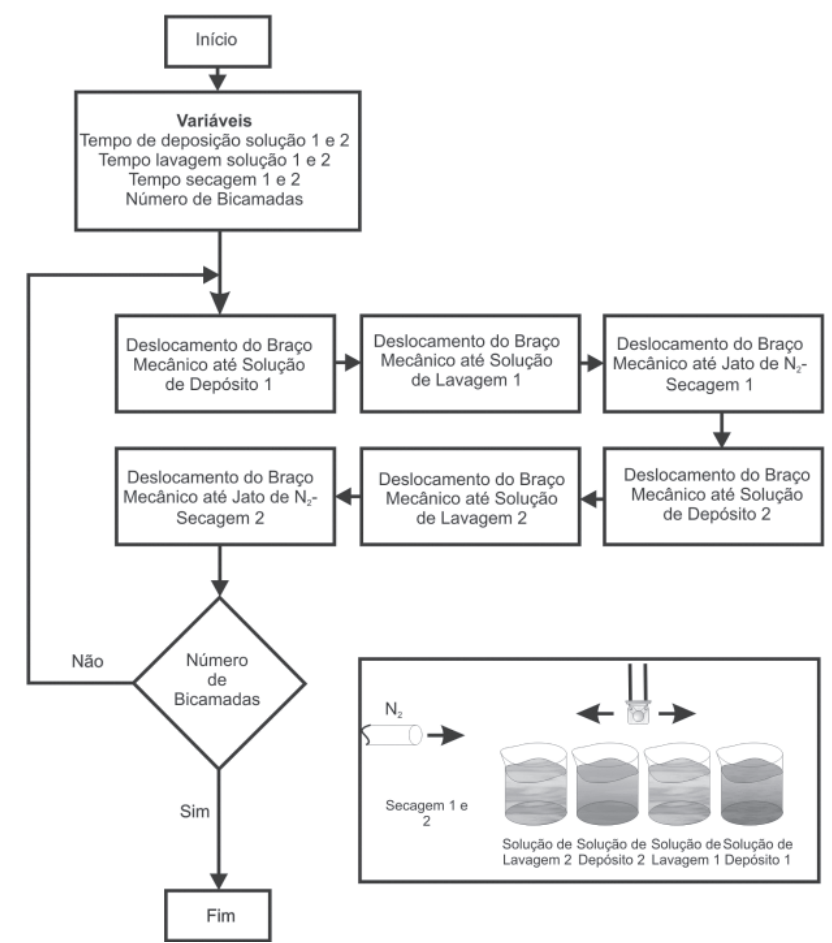

Figura 3. Fluxograma do programa

Ao ser acionado, o software requer que sejam introduzidas as seguintes variáveis, referentes a cada etapa do processo:

1- número de bicamadas desejado;

2- tempo de deposição na primeira solução; 
3- tempo de lavagem na primeira solução de lavagem;

4- tempo de secagem da primeira monocamada;

5- tempo de deposição na segunda solução;

6- tempo de lavagem na segunda solução de lavagem e

7- tempo de secagem da segunda monocamada.

Após a introdução destas variáveis, o dispositivo começa a funcionar, descrevendo toda a trajetória programada (Figura 3). Após o término de uma bicamada o programa reinicializa e dá continuidade à preparação de outra bicamada, e assim sucessivamente, até o final do processo.

\section{REFINAMENTO E TESTE DO DISPOSITIVO}

Com o objetivo de testar o dispositivo construído, prepararamse filmes automontados de polímeros condutores. Desta forma, foram analisados alguns parâmetros das etapas da montagem dos filmes, como o tempo que o substrato permanecia na solução de lavagem e na etapa de secagem. Esta fase teve como principal objetivo a calibração do braço mecânico de forma que seu movimento reproduzisse, da melhor maneira possível, o movimento natural de construção de um filme automontado preparado manualmente.

O processo de lavagem foi otimizado, buscando o menor tempo possível de permanência do substrato na solução. O tempo de $5 \mathrm{~s}$ foi suficiente para esta etapa, pois antes do início da cronometragem, o braço mecânico realiza um leve movimento de zigue e zague, comandado pelo programa, no interior da solução de lavagem. Este procedimento permitiu a retirada de resíduos poliméricos provenientes das soluções de depósito, que poderiam prejudicar a fabricação das monocamadas.

O processo de secagem foi otimizado de forma a evitar a contaminação das soluções de depósito, que poderia ocorrer através do transporte de gotas pelo substrato. Para isso, calibrou-se a válvula solenóide de forma que seu acionamento fosse estabelecido alguns segundos antes da parada do substrato na saída do jato de secagem. Além disso, uma pequena bolsa de papel absorvente foi colocada sob o local de secagem, de maneira que quando o braço mecânico estacionasse na posição de secagem, o substrato tocasse o papel, permitindo a sorção prévia de gotas excedentes da solução polimérica. Este procedimento reduziu drasticamente o tempo de secagem (2 min) e otimizou a reprodutibilidade dos filmes.

\section{Caracterização eletroquímica dos filmes preparados}

Para ilustrar o funcionamento do dispositivo construído foram preparados filmes de polímeros condutores contendo 40 bicamadas de poli(o-metoxianilina) e poli(ácido-3-tiofeno acético). Para comparação foi também preparado manualmente um filme nas mesmas condições descritas acima. Cada monocamada foi depositada utilizando um tempo de permanência de 3 min na solução de depósito. Como o procedimento manual era muito mais trabalhoso, a permanência do substrato na solução de depósito foi reduzida para $20 \mathrm{~s}$ para cada monocamada. Os tempos de lavagem e secagem foram os mesmos para ambos os filmes.

A resposta eletroquímica obtida em ambos procedimentos é apresentada na Figura 4. Como pode ser observado nesta figura, ambos os filmes apresentaram um comportamento eletroquímico semelhante. Entretanto, o filme automontado pelo método manual apresentou uma densidade de corrente menor que a do filme fabricado com o

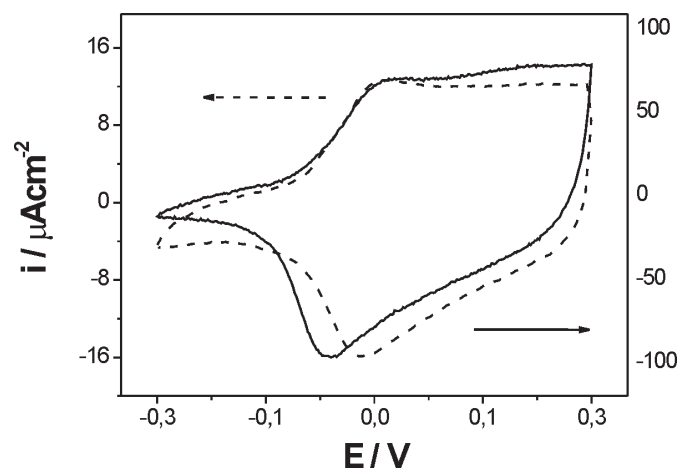

Figura 4. Comparação de dois filmes automontados obtidos pelo método usual (-----) e com o auxílio do dispositivo (- $(-)$. Voltametria cíclica de filmes automontados de POMA-PTAA sobre platina em cristal de quartzo, em acetonitrila contendo $\mathrm{LiClO}_{4} 0,1 \mathrm{M}$ como eletrólito suporte, $\mathrm{T}=25^{\circ} \mathrm{C}$, eletrodo de pseudo-referência de Ag, eletrodo auxiliar de platina, $v=20 \mathrm{mV} / \mathrm{s}$

auxílio do dispositivo. Isto não é surpreendente, pois o tempo de depósito no procedimento usual foi menor e, portanto, menos massa polimérica foi depositada sobre o eletrodo. Como a densidade de corrente é proporcional à massa depositada, ocorre esta diminuição na densidade de corrente.

\section{CONCLUSÕES}

Foi construído e testado um dispositivo automatizado para a construção de filmes automontados. O dispositivo é controlado por computador, o que oferece total flexibilidade quanto aos parâmetros de deposição: número de camadas, números de materiais, tempo de deposição, procedimento de lavagem e secagem entre as deposições. Para testar o dispositivo, foram construídos filmes automontados de poli(o-metoxianilina) e poli(ácido-3-tiofeno acético). Estes filmes foram comparados com filmes equivalentes, preparados pelo procedimento manual. Como esperado, ocorreram diferenças significativas entre os filmes. Além disso, o procedimento automatizado permite a obtenção de filmes automontados com propriedades reprodutíveis.

\section{AGRADECIMENTOS}

À CNPq e à FAPESP (proc. 01/01389-1) pelo apoio financeiro.

\section{REFERÊNCIAS}

1. Oliveira Jr, O. N.; Raposo, M.; Dhanabalan, A. Em Handbook of Surface and Interfaces of Materials; Nalwa, H.S., ed.; Academic Press, 2001, vol. 4, cap. 1 .

2. Paterno, L. G.; Mattoso, L. H. C.; Oliveira Jr., O. N.; Quim. Nova 2001, $24,228$.

3. Cheung, J. H.; Punkka, E.; Rikukawa, M.; Rosner, R. B.; Royappa, A. T.; Rubner, M. F.; Thin Solid Films 1992, 210/211, 246.

4. Decher, G.; Hong, J. D.; Schmitt, J.; Thin Solid Films 1992, 210/211, 831.

5. Ferreira, M.; Cheung, J. H.; Rubner, M. F.; Thin Solid Films 1994, 244, 806.

6. Nabok, A. V.; Hassen, A. K.; Ray, A. K.; Mater. Sci. Eng., C 1999, 8-9, 505 . 